\title{
La tarea del revisor de artículos para Actas Urológicas Españolas
}

\author{
Ruiz Cerdá JL. \\ Servicio de Urología. Hospital la Fe. Valencia. \\ Actas Urol Esp 2006; 30 (6): 555
}

$\mathrm{U}^{\mathrm{n}}$ na revista médica tiene como objetivo el recoger, con la máxima fiabilidad y exhaustividad posible, la actividad científica de una comunidad. En el caso de Actas Urológicas Españolas la de nuestra comunidad urológica.

Nuestra labor como editores es la de recoger el manuscrito, revisarlo, aconsejar las modificaciones que proponen los revisores y tomar la decisión de su publicación o no. Todo este proceso, se lleva a cabo siguiendo unas normas metodológicas, de medicina basada en la evidencia, éticas y de publicación. Las normas no las establecemos nosotros, sino que se encuentran aceptadas en la mayoría de revistas médicas y estandarizadas en múltiples trabajos y libros específicos sobre dicha materia.

La impresión que tienen los urólogos españoles de Actas Urológicas Españolas, no siempre es positiva en relación a su nivel científico. Creo que todos estamos de cuerdo en que es mejorable. Nuestro objetivo final es elevarlo. Teniendo claro este objetivo común, cada uno desde su posición, autor del manuscrito o revisor, tiene una responsabilidad diferente pero compartida y complementaria.

La labor que los revisores realizan es esencial para elevar el nivel científico de la revista. Ellos revisan el fondo del manuscrito. Pero también, la forma en que deben ser expresados los datos para su mejor comprensión y lectura. La revisión siempre es bien intencionada, pero está sometida a las normas antes comentadas. Actualmente estamos realizando un esfuerzo desde el comité editorial para mejorar nuestra labor. Este esfuerzo se traduce en la revisión del manuscrito, crítica y emisión de un informe detallado. Todo ello con la convicción de que, dedicarle un tiempo importante a la revisión del manuscrito, supone el mayor respeto que podemos tener hacia los autores del mismo. Intentamos huir de la mera clasificación: "aceptable o no aceptable" para publicación.

La actitud de los autores de los manuscritos frente a los informes emitidos por los revisores es esencial para nosotros. Nuestra intención no es disuadir, rechazar ni desanimarles en su objetivo final, que es la publicación del manuscrito. Todo lo contrario, nos mueve una crítica constructiva, de ayuda y mejora del mismo para tratar de darle brillantez y, sobre todo, para que la revista se beneficie de ello. Objetivo común de todos: autores y revisores.

Sin embargo, la revisión del manuscrito es una tarea humana y, como tal, está sometida a error. Además, pueden existir diferencias de opinión e interpretación. Por eso, se ofrece la posibilidad de respuesta y contrastación de ideas a los autores. Esta labor, en sí misma, ya es enriquecedora y eleva el nivel científico de nuestra revista. En ocasiones el informe de revisión no es bien comprendido por los autores causando insatisfacción y, en la mayoría de las ocasiones, sometiéndoles a realizar un trabajo extra. Nuestro objetivo con estos comentarios es mejorar el entendimiento entre la labor de los revisores y la de los autores.

Quiero finalizar expresando mi gratitud a todos los autores y revisores por el tiempo que dedican en la preparación y revisión de los manuscritos. Porque tengo el convencimiento de que a todos nos mueve una tarea común: lograr una mejor revista. 